\title{
A Comparison Between Using A Firefly Algorithm and A Modified PSO Technique for Stability Analysis of a PV System Connected to Grid
}

\author{
A.Elrheem E.A. Mostafa*, Naglaa K. Bahgaat** \\ *Electrical Power Eng. Dept. Faculty of Engineering Al-Azhar University Qena, Egypt \\ **Elec. Comm. Dept. Faculty of Eng. Canadian International College (CIC) 6 October City, Giza, Egypt \\ (d.rheem2017@gmail.com, nkbahgaat@yahoo.com)
}

Received: 25.11.2017 Accepted:30.12.2017

\begin{abstract}
The Photo Voltaic Systems (PVS) has become a very important source of renewable energy sources, as a result of the global energy crisis as well as environmental pollution resulting from conventional energy sou rces. One of the most important applications of (PVS) are those connected to the electrical grid, despite th e instability problems facing these systems. This paper studies the stability analysis of PVS connected to $g$ rid by using two modern techniques of artificial intelligence based Proportional-Integral (PI) controller. The se two modern techniques used in this paper are a Firefly Algorithm (FA), and Adaptive Acceleration Parti cle Swarm Optimization (AAPSO) technique in order to voltage stability of PVS connected to three phase electrical distribution network for any rang of solar radiation. This paper uses the MATLAB / SIMULINK software, it has been implemented for the comparison of the conventional PI controllers, FA, and AAPSO used for photovoltaic DC voltage control. This comparison has been carried out to compare the settling ti mes and overshoots of each technique, to find out whichever is most efficient for this purpose.
\end{abstract}

Keywords: Photo Voltaic Systems (PVS), Proportional-Integral (PI) controller, Firefly Algorithm (FA), Particle Swarm Optimization (PSO), and Adaptive Acceleration Particle Swarm Optimization (AAPSO).

\section{Introduction}

In recent years, it has become necessary to research the problems facing solar energy, so as to optimize the use of this clean and renewable energy. One of the biggest problems is the instability of PVS connected to an electrical grid. Recently researchers have been interested in Artificial Intelligence (AI) to solving these problems [1].

This paper studies the stability analysis of PVS connected to an electrical distribution network using PI controller based on two modern techniques of artificial intelligence, these two modern techniques are the Firefly Algorithm (FA), and Modified Particle Swarm Optimization or Adaptive Acceleration Particle Swarm Optimization (AAPSO) technique. The system which will be investigated in this paper is consists of a 3-phase grid connected with a PV system. A PV array (100-kWatt) is connected to grid (25kVolt) via a 3-phase Voltage Source Converter (VSC) and DC-DC boost converter. This paper is concerned with studying the voltage stability by conventional PI controllers because it is the most appropriate controller in case of photovoltaic systems connected to grid, and also is studied tuning PI controller by the Firefly Algorithm (FA), and Adaptive Acceleration Particle Swarm Optimization (AAPSO) technique to minimize the error of DC voltage thus make better use of the PV array. Figure 1 Shows conventional PI controller used to voltage DC regulation for the on-grid system used in this paper, all details of this system are described in [3]. 


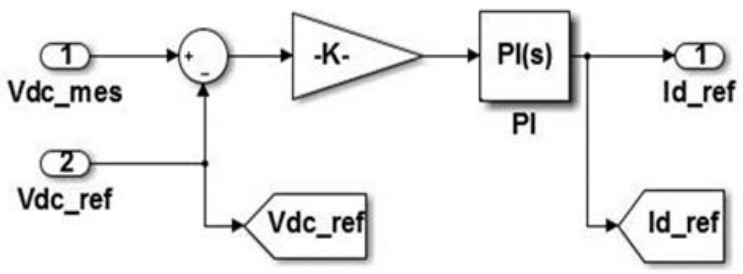

Fig. 1. SIMULINK model of Voltage regulation by using PI controller

The paper is organized as follows. Section 2 presents the Formulation of PI Parameters Tuning Problem. In section 3 we describe the basics of the FA. The Adaptive Acceleration PSO is explained in section 4. Numerical simulation and comparisons are provided in Section 5. Finally, some conclusions are drawn in Section 6.

\section{Formulation of PI Parameters Tuning Problem}

The conventional PI controller's is used in many industrial processes for its simplicity, and ease of use and applicability. On the other side, one of the most important problems in this control is tuning the Parameters which solve the best solution and how long it will take to reach these values [2]. To understand the formulation of PI parameters tuning problem we consider the block diagram shown in Figure 2. In this figure $\boldsymbol{G}_{\boldsymbol{P I}}(\boldsymbol{s})$ is the controller and $\boldsymbol{G}_{\boldsymbol{P}}(\boldsymbol{s})$ is the process to be controlled. In practice the output and the transfer function (in parallel structure) of the PI controller are given respectively by the equations [2]:

$$
\begin{aligned}
& u(t)=K_{p}(t)\left[e(t)+\frac{1}{T_{i}} \int e(t) d(t)\right] \\
& G_{P I}(s)=K_{p}\left[1+\frac{1}{T_{i} S}\right]
\end{aligned}
$$

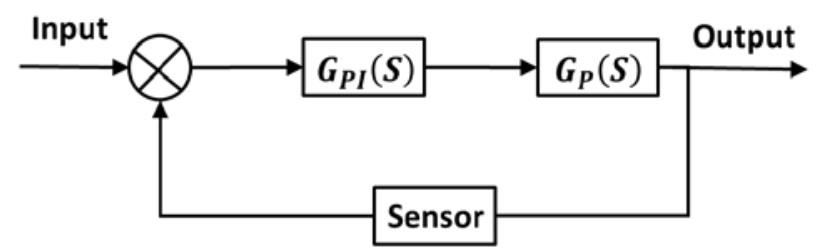

Fig. 2. Block diagram of a basic PI control system

For a given plant or process, the main goal of PI tuning problem, is to adjust optimally as fast as possible the PI controller parameters for getting a desired performance with a good closed loop time response of the considered process. Traditionally this problem has been dealt with by trial and error approaches. Recently, researchers who deal with artificial intelligence such as GA and PSO have become increasingly interested in meeting the required function of the PI, which is to reach optimal values or as close as possible in the smallest possible time [2, 6]. For this purpose, the proposed PI tuning based FA or AAPSO is schematically shown in Figure 3.

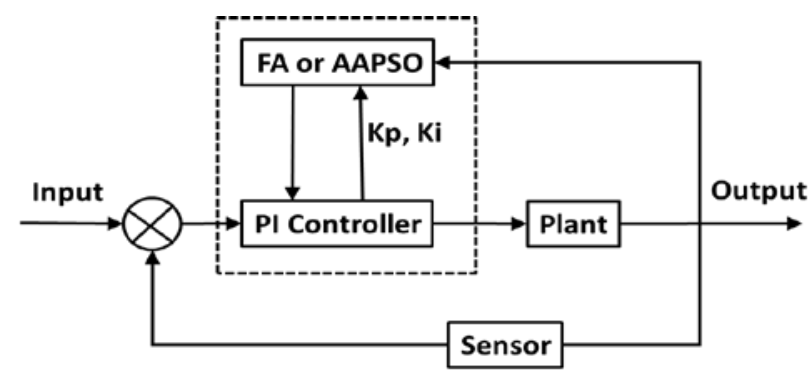

Fig. 3. PI tuning scheme with FA or AAPSO

The objective of the FA or AAPSO is to determine theses optimal parameters values, which minimizes the error in DC voltage, and to achieve the appropriate values in terms of settling time or overshoot in voltage, In order to voltage stability of a PV system connected to grid.

\section{Firefly Algorithm (FA)}

The firefly algorithm (FA) is one of the recent metaheuristic optimization methods inspired by the real fireflies' behavior. The idea of employing the cooperating firefly's agents to solve optimization problems was introduced by Xin-She Yang at Cambridge University and presented in [8] then extended in his further works [9]. It has been recently adapted for solving various design problems [10, 11].

Fireflies use flash signals to attract other fireflies for potential mates. All the fireflies are considered unisexual and their attraction is directly proportional to the intensity of their flash. Therefore, if a firefly particle had the choice of moving toward either of two fireflies, it will be more attracted toward the firefly with higher brightness and moves in that direction. If there are no fireflies nearby, the firefly will move in a random direction. The brightness of flash is associated with the fitness function. The light intensity also obeys the inverse square law as in Equation (3).

$$
I(r)=\frac{I_{s}}{\mathrm{r}^{2}}
$$

Where $\boldsymbol{I}(\boldsymbol{r})$ is the light intensity at a distance $\mathrm{r}$ and $\boldsymbol{I}_{\boldsymbol{s}}$ is the intensity at the source. For a given medium with fixed absorption coefficient $\boldsymbol{\gamma}$, the light intensity I varies with the distance $\boldsymbol{r}$ and is given in Equation (4) as 
INTERNATIONAL JOURNAL Of SMART GRID

E. A. Mostafa and N.K.Bahgaat. ,Vol. 1, No. 1, 2017

$$
\mathrm{I}=I_{0} * \exp \left(-\gamma \mathrm{r}^{2}\right)
$$

Here, $I_{0}$ is the original light intensity, $\gamma$ is the absorption coefficient and $r$ is the distance between the fireflies. As a firefly's attractiveness is proportional to the light intensity seen by adjacent fireflies, the attractiveness $\beta$ of a firefly can be defined as

$$
\beta=\beta_{0} * \exp \left(-\gamma \mathrm{r}^{\mathrm{m}}\right) \quad(m \geq 1)
$$

Where $\beta_{0}$ is the attractiveness at $r=0$. For two fireflies $\mathrm{i}$ and $\mathrm{j}, \mathrm{r}$ is calculated as

$$
r_{i j}=\sqrt{\sum_{K=1}^{d}\left(X_{i, K}-X_{j, K}\right)^{2}}=\left\|X_{i}-X_{j}\right\|
$$

(6)

Equation (6) is the distance between any two fireflies $\mathrm{i}$ and $\mathrm{j}$ at $X_{i}$ and $X_{j}$ respectively. In each generation, the fireflies move to nearby fireflies having more brightness as determined by Equation (7) as

$$
X_{i}=X_{i}+\beta_{0} * \exp \left(-\gamma r_{i . j}{ }^{2}\right)\left(X_{i}-X_{j}\right)+\alpha \varepsilon
$$

Where $\boldsymbol{\alpha}$ is the randomization parameter and $\varepsilon$ is the vector of random numbers taken from Gaussian distribution. Here $\alpha$ controls the step size.

\subsection{Implementation of Firefly Algorithm for Tuning PI}

\section{Parameters}

Similar to other new optimization methods, firefly algorithm generates random initial population of feasible candidate solutions. All fireflies of the population are handled in the solution search space with the aim to guide the search to the best location in the search space using their flashing light (Fitness) and randomness. Each firefly in the population moves in the three-dimensional (number of decision variable) search space with an attractiveness that is dynamically updated based on the knowledge of the firefly and its neighbor's [2, 9].

Applying this search mechanism over the iterations, the FA find progressively the optimal set of PI parameters, while minimizing the fitness function. The flow chart of the proposed firefly algorithm for PI controller is shown in Figure 4.

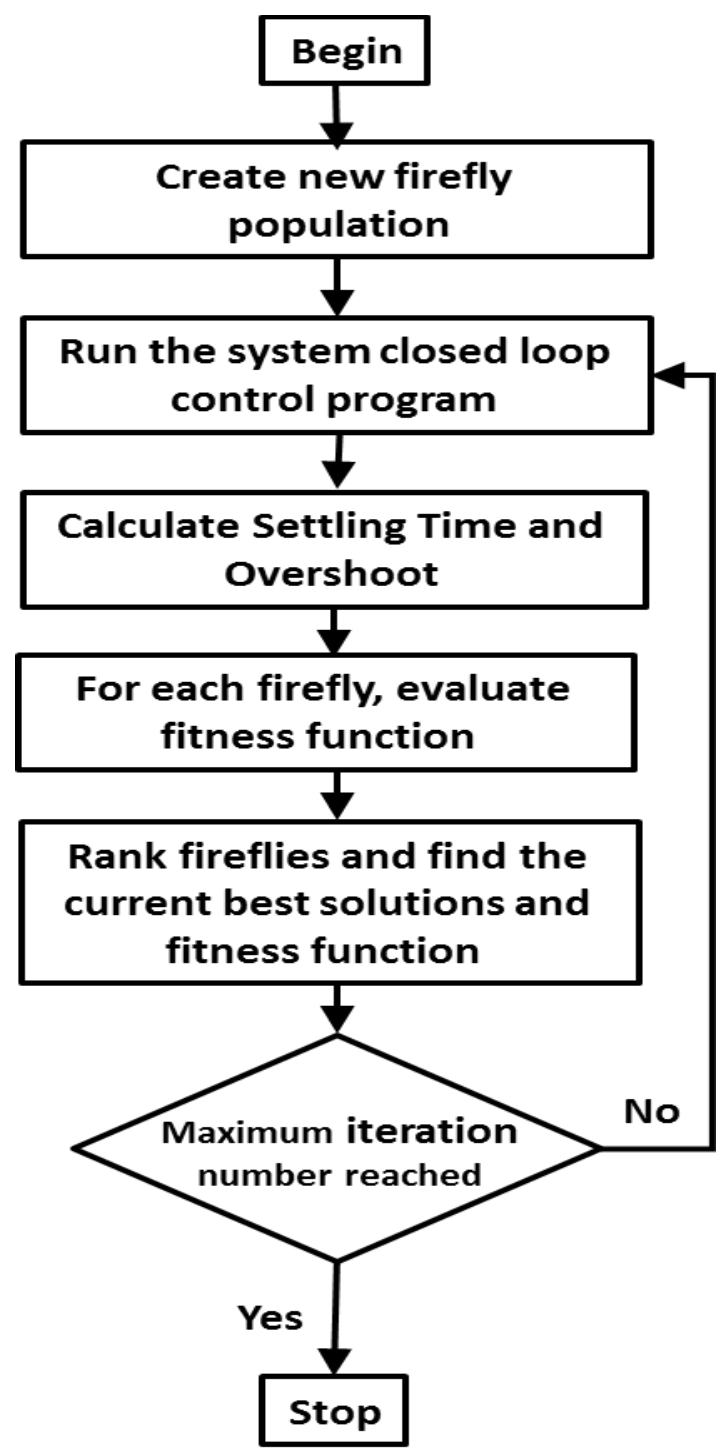

Fig. 4. The flowchart of FA for PI controller.

\section{Adaptive Acceleration PSO}

PSO is a grouping of particles and supports the gathering in his behavior is mainly based on the bird's behavior, as described in [12]. Adaptive Acceleration PSO is modified technique have emerged to improve PSO algorithms, by modification Acceleration Coefficients, where $C_{1}, C_{2}$ which described in [10]; $C_{1}$ and $C_{2}$ values will change linearly with time, this method studies how to deal with the weight and acceleration factors and how to change acceleration coefficients exponentially as contained in $C_{1}$ and $C_{2}$ vary adaptation parameters according to the fitness value of $g_{b e s t}$ and $P_{\text {best }}$ as contained in [13-16] becomes:

$$
V_{i}^{(t+1)}=W^{(t)} V_{i}^{(t)}+C_{1}^{(t)} r_{1} *\left(P_{\text {best }}{ }^{(t)}-X_{i}^{(t)}\right)+
$$


$C_{2}{ }^{(t)} r_{2} *\left(g_{\text {best }}{ }^{(t)}-X_{i}^{(t)}\right)$

(8)

$$
\begin{aligned}
& \mathrm{W}^{(t)}=W_{0} * \exp \left(-\alpha_{W} * t\right) \\
& C_{1}{ }^{(t)}=C_{10} * \exp \left(-\alpha_{c} * t * K_{c}{ }^{(t)}\right)
\end{aligned}
$$

(10)

$$
C_{2}{ }^{(t)}=C_{20} * \exp \left(-\alpha_{c} * t * K_{c}{ }^{(t)}\right)
$$

$$
\begin{aligned}
& \alpha_{c}=\frac{-1}{t_{\max }} \ln \left(\frac{C_{2 o}}{C_{1 o}}\right) \\
& K_{c}^{(t)}=\frac{F_{m}^{(t)}-g_{\text {best }}(t)}{F_{m}{ }^{(t)}} \\
& X_{i}^{(t+1)}=X_{i}^{(t)}+V_{i}^{(t+1)}
\end{aligned}
$$

Where :

$V_{i(t)} \quad$ Velocity of the particle i at iteration $\mathrm{t}(\mathrm{m} / \mathrm{s})$

$X_{i(t)} \quad$ The Current position of particle i at iteration $\mathrm{t}$ (m)

$W^{(t)} \quad$ The inertia weight factor

$g_{\text {best }} \quad$ The Global best position (m)

$C_{1}, C_{2}$ The constant representing the weighing of the stochastic acceleration terms that pull each particle towards $P_{\text {best }}$ and $g_{\text {best }}$ positions

$C_{1}{ }^{(t)} \quad$ Acceleration coefficient at iteration

$i \quad$ Equal 1 or 2

$t \quad$ The iteration number

ln The neperian logarithm

$\alpha_{w} \quad$ Is determined with respect to initial and final values of $W$ with the same manner as $\alpha_{c}$ described in [14].

$K_{c}{ }^{(t)} \quad$ Determined based on the fitness value of $g_{\text {best }}$ and $P_{\text {best }}$ at iteration $\mathrm{t}$

$W_{o}$, Initial values of inertia weight factor and $C_{i o} \quad$ acceleration coefficients respectively with $i$ $=1$ or 2 .

$F_{m}{ }^{(t)} \quad$ The mean value of the best positions related to all particles at iteration $t$

\section{Simulation and Results}

The system which will be investigated in this paper is consists of a 3-phase grid connected with a PV system. A PV array (100-kWatt) is connected to grid (25-kVolt) via a 3-phase Voltage Source Converter (VSC) and DC-DC boost converter. This system described in [4].

In grid connected system, the system voltage should synchronize with the grid voltage. For this purpose the inverter should work in the grid frequency and voltage. The control scheme of grid connected inverter consisting of three parts. Direct and quadrature axis current reference generator, PLL and direct and quadrature (d-q) frame generation of grid voltage and current, Conversion voltage generation, Pulse Width Modulation (PWM) reference generation, Sine PWM with third harmonic injection for switching the inverter. Direct and quadrature axis current (Id-Iq) reference generation is described in [4]. The DC link voltage feedback and reference dc voltage are given to Id-Iq reference generator. After making per unit the error signal is given to PI controller to produce $d$ axis reference, the $\mathrm{q}$ axis component is set to be zero [4,17].

The grid voltage and current are given to a discrete three phase PLL to produce angle $\theta$, where $\theta=\omega \mathrm{t}$ and $\omega$ is the utility grid fundamental frequency in the grid-connected system application. And using Park's transformation current and voltage three phase (a, b, and c) are converted to (d, and q) components [18, 19].The PV array consists of 330 Sun power modules (SPR-30E-WHT-D), the maximum power from PV array $=100.7 \mathrm{Kw}$. The manufacturer specifications for one module described in [20] are shown in Table 1.

Table 1. One module parameters of PV array

\begin{tabular}{|l|l|}
\hline Number of cells per module & 96 \\
\hline Open circuit voltage (Voc) & $64.2 \mathrm{~V}$ \\
\hline Short circuit current (Isc) & $5.96 \mathrm{~A}$ \\
\hline Voltage at maximum power (Vmp) & $54.7 \mathrm{~V}$ \\
\hline Current at maximum power (Imp) & $5.58 \mathrm{~A}$ \\
\hline
\end{tabular}

\subsection{Case 1 without Controller}

Firstly perform simulation of the system, simulation where the time $=6 \mathrm{sec}$, the comparison of error of DC voltage without controller, this is shown in Figure 5. 
INTERNATIONAL JOURNAL Of SMART GRID

E. A. Mostafa and N.K.Bahgaat. ,Vol. 1, No. 1, 2017

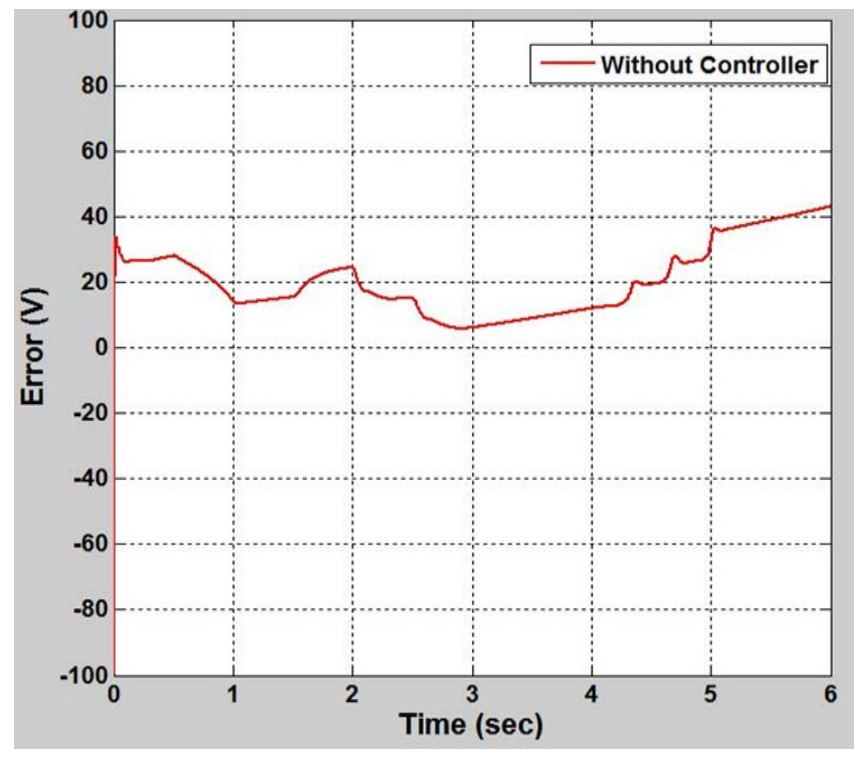

Fig. 5. Error of DC voltage without controller

\subsection{Case 2 with Conventional PI Controller}

Secondly perform simulation of the system with conventional PI. Figure 6 shows the settling time and overshoot voltage with the conventional PI controllers.

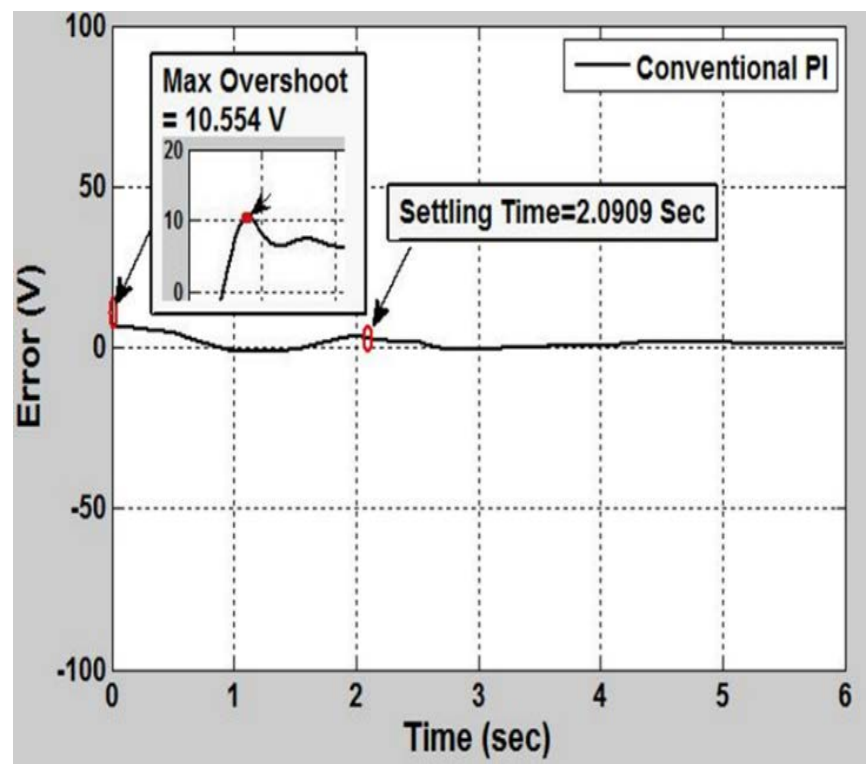

Fig. 6. Error of DC voltage with conventional PI controller

\subsection{Case 3 with PI Controller based FA}

Figure 7. Show SIMULINK model of voltage regulation by using PI controller based FA. All parameters of FA as shown in Table 2.

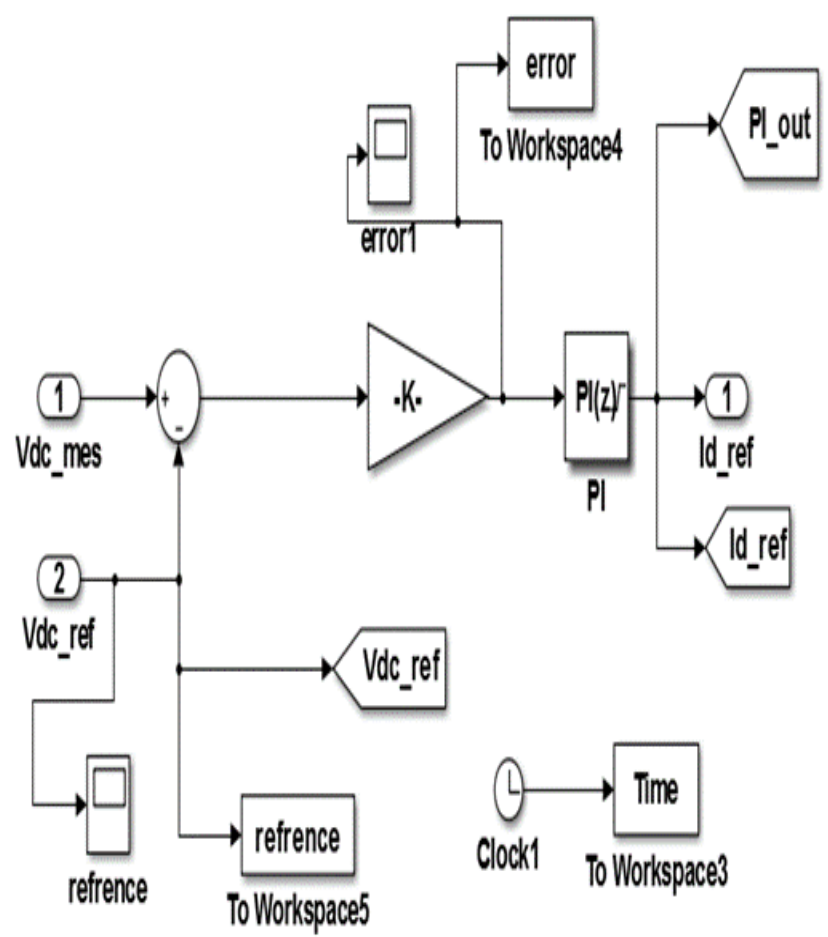

Fig. 7. SIMULINK model of Voltage regulation by using PI controller based FA

Table 2. The parameters of FA

\begin{tabular}{|l|l|}
\hline parameters & Quantity \\
\hline number of fireflies & 35 \\
\hline number of iterations & 500 \\
\hline Randomness $(\boldsymbol{\alpha})$ & 0.3 \\
\hline Absorption Coefficient $(\boldsymbol{\gamma})$ & 1.0 \\
\hline Attractiveness $(\boldsymbol{\beta}) \quad 0.2$ \\
\hline $\begin{array}{l}\text { The movement of firefly can be } \\
\text { controller parameter }(\delta)\end{array}$ & 0.97 \\
\hline
\end{tabular}

Perform simulation of the system, by using PI controller based FA, writing the best results and compare the results. The top 10 results are shown in Table 3, which explains that the best result in case Number 4. The settling time and overshoot voltage of the best case are shown in Figure 8 . 
Table 3. The Best Results of FA

\begin{tabular}{|l|l|l|l|l|l|}
\hline & Kp & Ki & $\begin{array}{l}\text { Settling } \\
\text { Time }\end{array}$ & $\begin{array}{l}\text { Time at } \\
\text { Max }\end{array}$ & $\begin{array}{l}\text { Over } \\
\text { shoot }\end{array}$ \\
\hline 1 & 81.474 & 58.225 & 0.0109 & 0.0073 & 8.6816 \\
\hline 2 & 84.2769 & 44.036 & 0.0108 & 0.0072 & 8.6276 \\
\hline 3 & 178.2045 & 89.010 & 0.0108 & 0.0072 & 9.0648 \\
\hline 4 & 44.0890 & 1.8031 & $\mathbf{0 . 0 1 0 0 5}$ & 0.0071 & $\mathbf{8 . 0 2 1 0}$ \\
\hline 5 & 194.222 & 54.139 & 0.0107 & 0.0072 & 8.9774 \\
\hline 6 & 176.932 & 50.984 & 0.0109 & 0.0072 & 8.9811 \\
\hline 7 & 224.339 & 71.099 & 0.0109 & 0.0072 & 9.0001 \\
\hline 8 & 113.781 & 34.351 & 0.0107 & 0.0072 & 8.7160 \\
\hline 9 & 106.425 & 4.1149 & 0.0104 & 0.0072 & 8.5875 \\
\hline 10 & 47.3410 & 3.1180 & 0.0102 & 0.0071 & 8.0487 \\
\hline
\end{tabular}

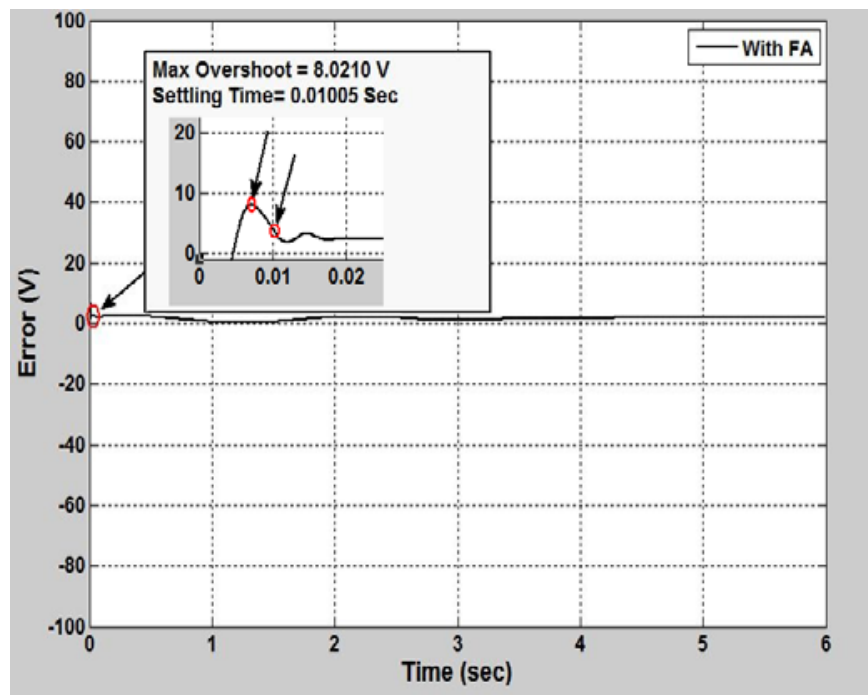

Fig. 8. Error of DC voltage with FA

\subsection{Case 5 with PI Controller based AAPSO}

Perform simulation of the system, by using PI controller based AAPSO, all parameters of PSO with difference percentage towards personal optimum $\left(\boldsymbol{C}_{\mathbf{1 0}}=3, \boldsymbol{C}_{\mathbf{2 0}}=3.05\right)$ in equations (11), (12). The top 10 results are shown in Table 4, which explains that the best result in case Number 3. The settling time and overshoot voltage of the best case are shown in Figure 9.

Table 4. The Best Results of AAPSO

\begin{tabular}{|l|l|l|l|l|l|}
\hline & Kp & Ki & $\begin{array}{l}\text { Settling } \\
\text { Time }\end{array}$ & $\begin{array}{l}\text { Time at } \\
\text { Max }\end{array}$ & $\begin{array}{l}\text { Oversho } \\
\text { ot }\end{array}$ \\
\hline
\end{tabular}

\begin{tabular}{|l|l|l|l|l|l|}
\hline 1 & 285.6 & 192.69 & 0.0111 & 0.0073 & 9.2488 \\
\hline 2 & 59.94 & 61.321 & 0.0158 & 0.0072 & 8.5716 \\
\hline 3 & 47.09 & 5.155 & $\mathbf{0 . 0 1 0 3}$ & 0.0071 & $\mathbf{8 . 0 6 4 4}$ \\
\hline 4 & 67.63 & 4.53 & 0.0105 & 0.0072 & 8.2665 \\
\hline 5 & 312.5 & 185.87 & 0.0111 & 0.0073 & 9.2468 \\
\hline 6 & 205.6 & 25.955 & 0.0109 & 0.0072 & 8.9111 \\
\hline 7 & 204.2 & 319.31 & 0.0113 & 0.0073 & 9.6178 \\
\hline 8 & 242.8 & 44.727 & 0.0108 & 0.0072 & 8.9559 \\
\hline 9 & 107.9 & 544.36 & 0.0296 & 0.0074 & 11.0892 \\
\hline 10 & 267.8 & 443.59 & 0.0115 & 0.0073 & 9.7733 \\
\hline
\end{tabular}

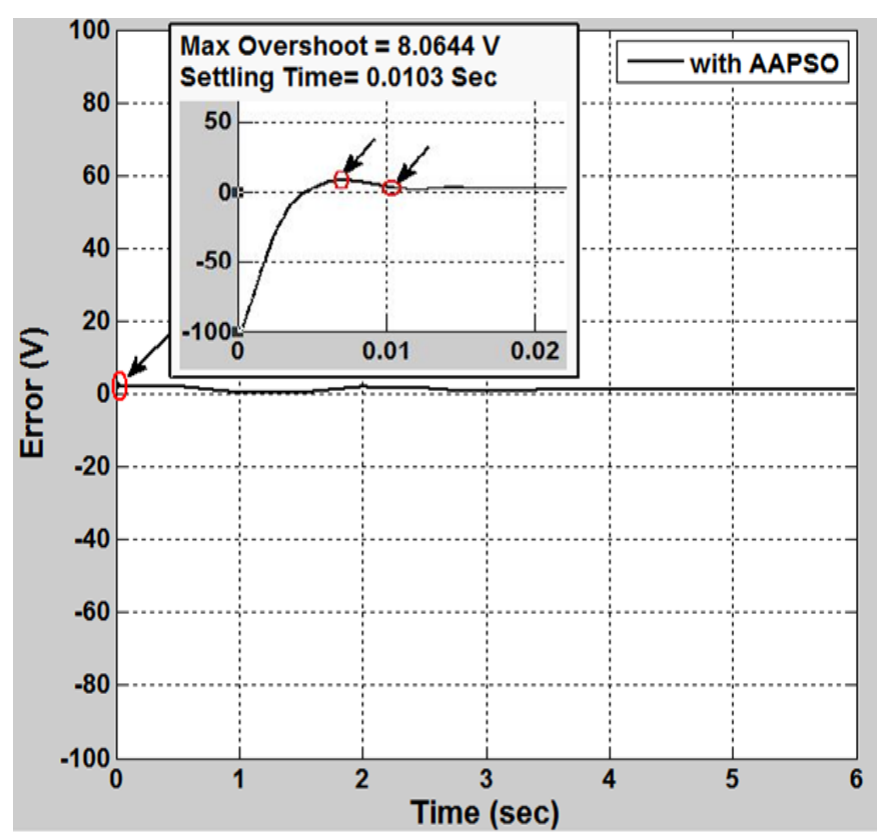

Fig. 9. Error of DC voltage with AAPSO

Finally a comparison between best case of FA, and AAPSO technique, the settling times and overshoots with the tow of intelligent controllers are better than the outputs of conventional PI Controller, and (FA) is the better's technique for this purpose. Are shown in Figures 10, 11, and Table 5. 
INTERNATIONAL JOURNAL Of SMART GRID

E. A. Mostafa and N.K.Bahgaat. ,Vol. 1, No. 1, 2017

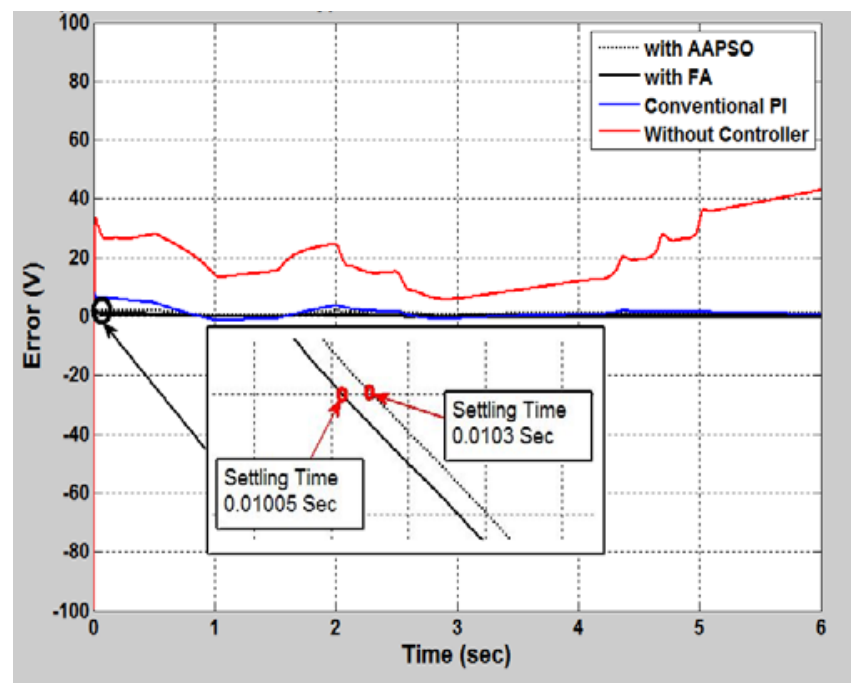

Fig. 10. Comparison between FA, and AAPSO

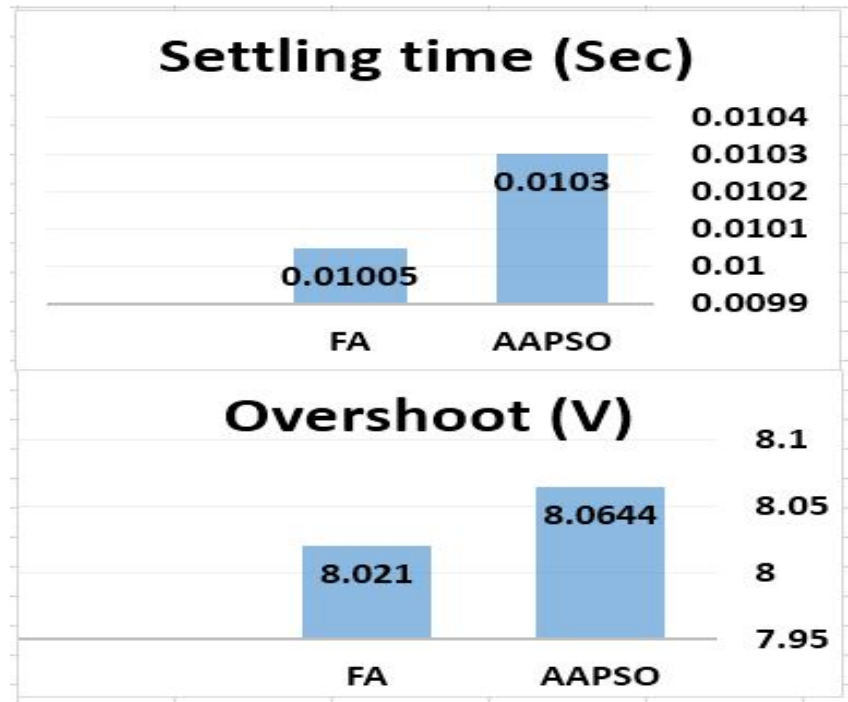

Fig. 11. Comparison between Settling times and overshoots by FA, and AAPSO

Table 5. Comparison of the best results between PSO, AWPSO, and AAPSO

\begin{tabular}{|l|l|l|l|}
\hline & $\begin{array}{l}\text { Convent- } \\
\text { ional PI }\end{array}$ & $\begin{array}{l}\text { PI based } \\
\text { FA }\end{array}$ & $\begin{array}{l}\text { PI based } \\
\text { AAPSO }\end{array}$ \\
\hline KP & 14.9830 & 44.0890 & 47.09 \\
\hline KI & 12.0947 & 1.8031 & 5.155 \\
\hline $\begin{array}{l}\text { Settling } \\
\text { Time (Sec) }\end{array}$ & 2.0909 & 0.01005 & 0.0103 \\
\hline $\begin{array}{l}\text { Time at } \\
\text { max (Sec) }\end{array}$ & 0.0080 & 0.0071 & 0.0071 \\
\hline $\begin{array}{l}\text { Over } \\
\text { Shoot (V) }\end{array}$ & 10.554 & 8.0210 & 8.0644 \\
\hline
\end{tabular}

\section{Conclusion}

In this paper tow modern intelligent techniques are used for a photo-voltaic generation (PVG) system connected to three phase electrical distribution network, the settling times and overshoot voltage values with the PI controller based FA, and Adaptive Acceleration Particle Swarm Optimization(AAPSO) techniques are compared with the results using the conventional PI controllers, the (FA) technique gives the best results, the values of the settling time and over shoot voltage are smaller than its values by using the other techniques.

So, using (FA) is preferred to make a tuning of the PI controller of a PV System connected with an Electrical Distribution Network.

\section{References}

[1] S. Lakshmanan, A. Jain and B. Rajpurohit, "An approach to improve power flow control and stability analysis for grid connected solar PV system", 2015 International Conference on Circuits, Power and Computing Technologies [ICCPCT-2015], pp. 1-5, 2015.

[2] M. Eltawil and Z. Zhao, "Grid-connected photovoltaic power systems: Technical and potential problems-A review", Renewable and Sustainable Energy Reviews, vol. 14, no. 1, pp. 112-129, 2010.

[3] A.Elrheem E.A. Mostafa, Naglaa K. Bahgaat, M. I. El sayed and E. A. Othman, "Voltage Stability for a Photovoltaic System Connected to Grid by Using Genetic Algorithm Technique", International Journal of Grid and Distributed Computing, vol. 10, no. 4, pp. 3342, 2017.

[4] S. Chu, Y. Cui and N. Liu, "The path towards sustainable energy", Nature Materials, vol. 16, no. 1, pp. 16-22, 2016.

[5] R. Belu, "Artificial Intelligence Techniques for Solar Energy and Photovoltaic Applications", Handbook of Research on Solar Energy Systems and Technologies, pp. 376-436, 2013.

[6] A. Pospischil, M. Furchi and T. Mueller, "Solar-energy conversion and light emission in an atomic monolayer p-n diode", Nature Nanotechnology, vol. 9, no. 4, pp. 257-261, 2014.

[7] G. Chaurasia, A. Singh, S. Agrawal and N. Sharma, "A meta-heuristic firefly algorithm based smart control strategy and analysis of a grid connected hybrid photovoltaic/wind distributed generation system", 
INTERNATIONAL JOURNAL of SMART GRID

E. A. Mostafa and N.K.Bahgaat. ,Vol. 1, No. 1, 2017

Solar Energy, vol. 150, no. 2, pp. 265-274, 2017.

[8] Balachennaiah, P., M. Suryakalavathi, and Palukuru Nagendra. "Optimizing real power loss and voltage stability limit of a large transmission network using firefly algorithm." Engineering Science and Technology, an International Journal 19.2, pp. 800-810, 2016.

[9] G. BAYRAK, and C. Mehmet, "Modeling of the photovoltaic generator at $3.6 \mathrm{~kW}$ power with simlink modeling $3.6 \mathrm{kw}$ installed power PV generator with matlab simulink", Erciyes University Institute of Science and Technology Magazine, vol. 3, pp. 3-28, 2016.

[10] S. Singh, R. Verma, A. Shakya and S. Pratap Singh, "Frequency Regulation of Micro-grid Connected Hybrid Power System with SMES", Technology and Economics of Smart Grids and Sustainable Energy, vol. 2, no. 1, 2017.

[11] N. K. Bahgaat, M. I. El-Sayed, M. A. Moustafa Hassan and F. Bendary, "Load Frequency Control in Power System via Improving PID Controller Based on Particle Swarm Optimization and ANFIS Techniques", International Journal of System Dynamics Applications, vol. 3, no. 3, pp. 1-24, 2015.

[12] A. M. Ali, M. Ebrahim and M. A. Moustafa Hassan, "Automatic Voltage Generation Control for Two Area Power System Based on Particle Swarm Optimization", Indonesian Journal of Electrical Engineering and Computer Science, vol. 2, no. 1, p. 132, 2016.

[13] Hennes, Rania Helmy Mansour. Development of advanced controllers using adaptive weighted PSO algorithm with applications. Diss. Cairo University, 2012.

[14] H. Rezk, A. Fathy and A. Abdelaziz, "A comparison of different global MPPT techniques based on metaheuristic algorithms for photovoltaic system subjected to partial shading conditions", Renewable and Sustainable Energy Reviews, vol. 74, pp. 377-386, 2017.

[15]M. Ebrahim El sayed, "Voltage Regulation for a Photovoltaic System Connected to Grid by Using a Swarm Optimization Techniques”, International Journal of Scientific \& Engineering Research [IJSER], vol. 8, no. 1, pp. 33-37, 2017.

[16] I. Posharp, "The manufacturer specifications of (SPR305E-WHT-D 305 Watt) Solar Panel from SunPower", Posharp.com. [Online]. Available: http://www.posharp.com/spr-305e-wht-d-solar-panelfrom-sunpower_p1621616600d.aspx. [Accessed: 28Apr- 2017]. 